\title{
Kinetic Studies of the Solvolyses of 2,2,2-Trichloro-1,1-Dimethylethyl Chloroformate
}

\author{
Han Joong Koh, ${ }^{*}$ Suk Jin Kang, and Dennis N. Kevill ${ }^{\dagger}$ \\ Department of Science Education, Jeonju National University of Education, Jeonju 560-757, Korea \\ *E-mail: hankoh@jnue.kr \\ ${ }^{\dagger}$ Department of Chemistry and Biochemistry, Northern Illinois University, DeKalb, Illinois 60115-2862, USA \\ Received December 7, 2009, Accepted January 29, 2010
}

\begin{abstract}
The rate constants of solvolyses of 2,2,2-trichloro-1,1-dimethylethyl chloroformate (I) in 33 solvents can be well correlated using the extended Grunwald-Winstein equation, with incorporation of the $\mathrm{N}_{\mathrm{T}}$ solvent nucleophilicity scale and the $\mathrm{Y}_{\mathrm{Cl}}$ solvent ionizing scale, with sensitivities towards changes in the scale having values of $1.42 \pm 0.09$ for $l$ and $0.39 \pm 0.05$ for $m$, respectively. The activation enthalpies are $\Delta \mathrm{H}^{\neq}=12.3$ to $14.5 \mathrm{kcal} \cdot \mathrm{mol}^{-1}$ and the activation entropies are -28.2 to $-35.5 \mathrm{cal} \cdot \mathrm{mol}^{-1} \cdot \mathrm{K}^{-1}$, consistent with the proposed bimolecular reaction mechanism. The kinetic solvent isotope effect of $2.14 \mathrm{in} \mathrm{MeOH} / \mathrm{MeOD}$ is in accord with a bimolecular mechanism, probably assisted by general-base catalysis.
\end{abstract}

Key Words: 2,2,2-Trichloro-1,1-dimethylethyl chloroformate, Extended Grunwald-Winstein equation, Addition-Elimination mechanism, Kinetic solvent isotope effect

\section{Introduction}

The mechanism of acyl-transfer reactions have been investigated intensively for many years both experimentally ${ }^{1}$ and theoretically. ${ }^{2}$ The mechanisms of most of these reactions are, however, still not well established. The bimolecular solvolysis of acyl halides (RCOX) is believed to proceed either through a direct displacement mechanism $\left(\mathrm{S}_{\mathrm{N}} 2\right)$ or through an associative addition-elimination mechanism involving a tetrahedral intermediate. ${ }^{3}$ For acyl halides with a strong electron donating group, $\mathrm{R}$, a dissociative mechanism involving an acylium ion intermediate has also been invoked. ${ }^{4}$ The two types of mechanism, $\mathrm{S}_{\mathrm{N}} 2$ and stepwise addition-elimination, are also common for the bimolecular aminolysis of acyl halides. The aminolyses of acetyl chloride, $\mathrm{MeCOCl}$, and methyl chloroformate, $\mathrm{MeO}$ $\mathrm{COCl}$, have been proposed to proceed by rate-limiting breakdown of a zwitterionic tetrahedral intermediate, $\mathrm{T}^{ \pm}$, for weakly basic amines with a change to rate-limiting attack for more basic amines. $^{5}$

The overall picture as regards product formation can be expressed as in Scheme 1, with pathways involving substitution at the acyl carbon shown to the left (bimolecular) and pathways involving the direct loss of carbon dioxide accompanying the substitution to the right (unimolecular). In some instances, such as for the reaction of isopropyl chloroformate, the pathway involving the loss of carbon dioxide can also exhibit an elimination component, leading to alkene. ${ }^{6}$

The equation (1) represents the most general form of the sol-

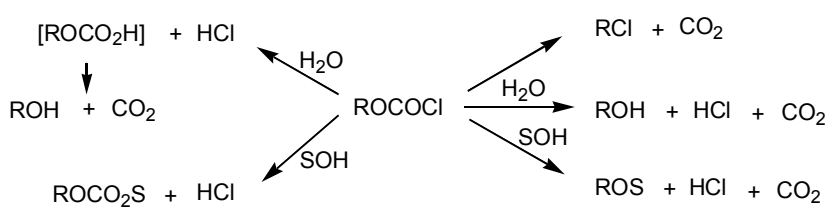

Scheme 1 volyses of several chloroformate esters. The dialkyl or alkyl aryl carbonate is formed by

$$
\begin{aligned}
& \mathrm{ROCOCl}+\mathrm{SOH} / \mathrm{H}_{2} \mathrm{O} \rightarrow \\
& \mathrm{ROCOOS}+\mathrm{ROS}
\end{aligned}+\mathrm{ROH}+\mathrm{CO}_{2}+\mathrm{HCl}
$$

nucleophilic attack of alcohol ( $\mathrm{SOH})$ at the acyl carbon. The alcohol or phenol product is formed either by a parallel attack by water to give the hydrogen carbonate ester, followed by the loss of $\mathrm{CO}_{2}{ }^{7}$, or by the attack of water on $\mathrm{R}^{+}$, formed by the loss of $\mathrm{CO}_{2}$ from an intermediate carboxylium ion $(\mathrm{ROCO})^{+}$. Capture of the $\mathrm{R}^{+}$by SOH leads to the ester (ROS) and capture by the chloride ion formed in the ionization will lead to a decomposition pathway (for the chloroformate ester reactant) to give $\mathrm{RCl}$. When feasible, an alternative decomposition pathway, involving the extraction of a $\beta$-proton from the $\mathrm{R}$ group and alkene formation, can also occur.

Two types of mechanism have been found to operate, postulated as an addition-elimination mechanism (Scheme 2), with the addition being rate limiting, and an ionization mechanism ${ }^{8}$ (Scheme 3).

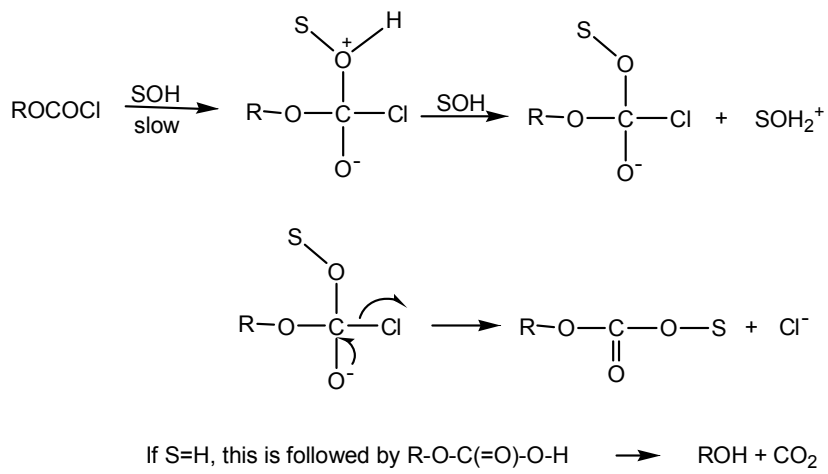



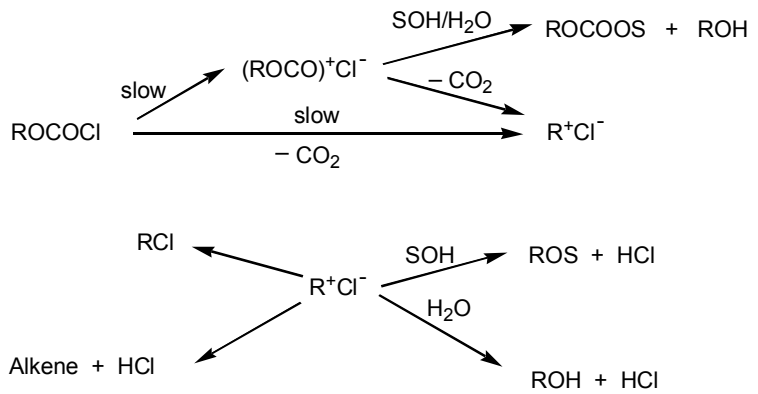

Scheme 3

The extended Grunwald-Winstein equation ${ }^{9}$ is used to correlate the rate constants of solvolysis reactions in terms of solvent ionizing power ${ }^{9 \mathrm{a}-\mathrm{e}}$ and solvent nucleophilicity. ${ }^{9 \mathrm{f}-\mathrm{h}}$ In equation (2), $\mathrm{k}$ and $\mathrm{k}_{\mathrm{o}}$ represent the rate constants of solvolysis in a given solvent and in a standard solvent ( $80 \%$ ethanol), respectively; $l$ represents the sensitivity to changes in solvent nucleophilicity $\left(\mathrm{N}_{\mathrm{T}}\right) ; m$ represents the sensitivity to changes in the solvent ionizing power $\left(\mathrm{Y}_{\mathrm{X}}\right.$, for a leaving group $\left.\mathrm{X}\right)$; and $\mathrm{c}$ represents a constant (residual) term.

$$
\log \left(\mathrm{k} / \mathrm{k}_{\mathrm{o}}\right)=l \mathrm{~N}_{\mathrm{T}}+m \mathrm{Y}_{\mathrm{X}}+\mathrm{c}
$$

In view of the often suggested mechanistic change for solvolysis of chloroformate esters from rate-limiting ionization (for alkyl groups $\mathrm{R}$ in $\mathrm{ROCOCl}$ with concurrent or subsequent fragmentation) to addition-elimination with the addition step rate-limiting, we conducted kinetic studies on the solvolysis reactions of 2,2,2-trichloro-1,1-dimethylethyl chloroformate (I) in pure and binary solvents, as shown (for an aqueous alcohol solvents) in equation (3). For non-solvolytic substitutions, it has been proposed that variation in the R group of ROCOX can lead to a change in the rate-limiting step $(r l s)$ from addition to elimination within the addition-elimination mechanism. ${ }^{10}$

Compound I can be considered as a derivative of tert-butyl chloroformate, with one of the methyl groups replaced by a trichloromethyl group. This involves replacing a group with a Taft polar substituent constant of zero (by definition) with a group with a very large positive value of $2.65 .^{11}$ This will cause an enormous difference in the electronic effects of the alkyl group.

The tert-butyl chloroformate decomposes rapidly at room temperature with ejection of carbon dioxide and formation of isobutylene and hydrogen chloride. ${ }^{12}$ Replacement of the tertbutyl group by the bridgehead 1-adamantyl group gives a more stable tertiary chloroformate ester and kinetic and product studies of its decomposition in inert solvents ${ }^{13}$ and of its solvolyses ${ }^{14}$ indicate an ionization-fragmentation mechanism in a wide range of solvents. Only in $100 \%$ ethanol was a small amount of the dicarbonate formed by attack of the solvent at the acyl carbon observed. It is of interest to see whether the introduction of the three chlorine atoms into the tert-butyl group not only stabilizes I but also leads, due to the powerful electron-withdrawing properties of the trichloromethyl group, to a considerably reduced tendency to ionization and to a partial or complete switch to the addition-elimination pathway.
In addition to the application of the extended GrunwaldWinstein equation to the rate constants, the influence of temperature on the rate constants in the five solvents has been discussed by calculating activation enthalpies and entropies. In order to obtain further mechanistic information from the kinetic solvent isotope effect, the kinetic runs were performed in both deuterated methanol (MeOD) and normal methanol $(\mathrm{MeOH})$.

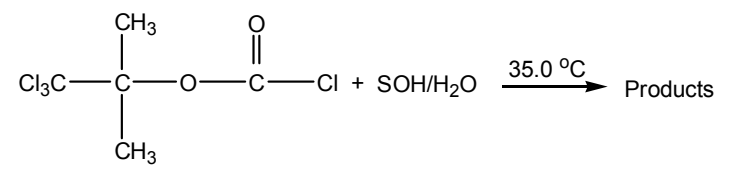

\section{Results and Discussion}

The solvolysis rate constants $(\mathrm{k})$ of 2,2,2-trichloro-1,1-dimethylethyl chloroformate (I) in 33 pure and binary solvents at $35.0^{\circ} \mathrm{C}$ are summarized in Table 1 .

In the present study, we are concerned with the rate constants of the solvolyses represented in equation (3). In most solvents, the reactions proceeded rapidly, therefore we employed the conductivity measurements, which were followed by recording the responses as a function of time. ${ }^{15}$ In order to promote a rapid dissolution in the solvent, the substrate was added as a small volume of a concentrated stock solution in acetonitrile such that the reaction solution contained about $0.1 \%$ acetonitrile.

The rate constants of ethanolysis of $\mathbf{I}$ was an order of magnitude lower $\left(\mathrm{k}=2.58 \times 10^{-4} \mathrm{~s}^{-1}\right.$ at $\left.25.0^{\circ} \mathrm{C}\right)$ than that of ethanolysis of phenyl chloroformate $(\mathrm{PhOCOCl})^{16}\left(\mathrm{k}=2.60 \times 10^{-3} \mathrm{~s}^{-1}\right.$ at $25.0^{\circ} \mathrm{C}$ ). This suggests that the 2,2,2-trichloro-1,1-dimethylethyl group is less electron-withdrawing than the phenyl group, such that it is less favorable for promoting nucleophilic attack at the electron-deficient carbonyl carbon. A larger steric effect may also be a factor.

The activation parameters, $\Delta \mathrm{H}^{\neq}$and $\Delta \mathrm{S}^{\neq}$, calculated from the $\mathrm{k}$ values at four temperatures for solvolyses of 2,2,2-trichloro-1,1-dimethylethyl chloroformate in 2 pure and 3 binary solvents, are shown in Table 2 . Relatively low $\Delta \mathrm{H}^{\ddagger}$ (12.3 to $\left.14.5 \mathrm{kcal} \cdot \mathrm{mol}^{-1}\right)$ and large negative $\Delta \mathrm{S}^{\neq}$values (-28.2 to -35.5 $\mathrm{cal} \cdot \mathrm{mol}^{-1} \mathrm{~K}^{-1}$ ) are within the ranges of those for a bimolecular reaction. The kinetic solvent isotope effect is relatively large, $\mathrm{k}_{\mathrm{MeOH}} / \mathrm{k}_{\mathrm{MeOD}}=2.14 \pm 0.08$, indicating that the bimolecular reaction is predominantly general-base catalyzed, ${ }^{3 \mathrm{c}}$ similar to the methanolysis of $n$-propyl chloroformate, which had a virtually identical value of $2.17 \pm 0.03 .^{17}$

The small positive $\Delta \mathrm{H}^{\ddagger}$ values and large negative $\Delta \mathrm{S}^{\ddagger}$ values are the expected characteristics for a relatively late TS with a large degree of bond making. ${ }^{18}$ The $\Delta \mathrm{S}^{\ddagger}$ values are in the range normally observed for associative $S_{\mathrm{N}} 2$ reactions or for additionelimination reactions with the addition step rate-limiting.

Calculated sensitivities obtained from the extended Grunwald-Winstein equation ${ }^{9}$ [eq. (2)] are shown as $1.42 \pm 0.09$ for $l$ and $0.39 \pm 0.05$ for $m$ in 33 solvents, as shown in Table 3 and Figure 1 with a multiple correlation coefficient of 0.945 . Often TFE-ethanol points lie below plots based on equation (2) ${ }^{19}$ but, 
Table 1. Rate constants of solvolysis of 2,2,2-trichloro-1,1-dimethylethyl chloroformate ${ }^{a}$ in various pure and mixed solvents at $35.0{ }^{\circ} \mathrm{C}$, as well as the $\mathrm{N}_{\mathrm{T}}$ and $\mathrm{Y}_{\mathrm{Cl}}$ values for the solvents.

\begin{tabular}{cccc}
\hline Solvent $^{b}$ & $10^{4} \mathrm{k}^{c}\left(\mathrm{~s}^{-1}\right)$ & $\mathrm{N}_{\mathrm{T}}{ }^{d}$ & $\mathrm{Y}_{\mathrm{Cl}}{ }^{e}$ \\
\hline $100 \% \mathrm{EtOH}$ & $5.50 \pm 0.03$ & 0.37 & -2.52 \\
$90 \%$ EtOH & $7.81 \pm 0.04$ & 0.16 & -0.94 \\
$80 \%$ EtOH & $8.70 \pm 0.04$ & 0.0 & 0.0 \\
$70 \%$ EtOH & $9.77 \pm 0.05$ & -0.20 & 0.78 \\
$60 \%$ EtOH & $11.0 \pm 0.2$ & -0.38 & 1.38 \\
$50 \%$ EtOH & $12.6 \pm 0.4$ & -0.58 & 2.02 \\
$40 \%$ EtOH & $13.8 \pm 0.4$ & -0.74 & 2.75 \\
$20 \%$ EtOH & $17.8 \pm 0.5$ & -1.16 & 4.09 \\
$100 \% \mathrm{MeOH}$ & $17.8 \pm 0.4$ & 0.17 & -1.20 \\
$90 \% \mathrm{MeOH}$ & $22.4 \pm 0.4$ & -0.01 & -0.20 \\
$80 \% \mathrm{MeOH}$ & $26.9 \pm 0.5$ & -0.06 & 0.67 \\
$70 \% \mathrm{MeOH}$ & $32.3 \pm 0.4$ & -0.40 & 1.46 \\
$60 \% \mathrm{MeOH}$ & $35.3 \pm 0.4$ & -0.54 & 2.07 \\
$50 \% \mathrm{MeOH}$ & $42.7 \pm 0.6$ & -0.75 & 2.70 \\
$40 \% \mathrm{MeOH}$ & $46.8 \pm 0.6$ & -0.87 & 3.25 \\
$90 \%$ Acetone & $1.32 \pm 0.03$ & -0.35 & -2.39 \\
$80 \%$ Acetone & $2.20 \pm 0.02$ & -0.37 & -0.83 \\
$70 \%$ Acetone & $2.77 \pm 0.03$ & -0.42 & 0.17 \\
$60 \%$ Acetone & $2.86 \pm 0.03$ & -0.52 & 1.00 \\
$50 \%$ Acetone & $3.38 \pm 0.04$ & -0.70 & 1.73 \\
$40 \%$ Acetone & $4.07 \pm 0.05$ & -0.83 & 2.46 \\
$30 \%$ Acetone & $4.68 \pm 0.04$ & -0.96 & 3.21 \\
$20 \%$ Acetone & $5.25 \pm 0.03$ & -1.11 & 3.77 \\
$80 \%$ TFE & $0.0905 \pm 0.0003$ & -2.19 & 2.90 \\
$70 \%$ TFE & $0.176 \pm 0.003$ & -1.98 & 2.96 \\
$50 \% \mathrm{TFE}$ & $0.678 \pm 0.005$ & -1.73 & 3.16 \\
$80 \% \mathrm{HFIP}$ & $0.0105 \pm 0.0004$ & -3.84 & 4.31 \\
$70 \% \mathrm{HFIP}$ & $0.0331 \pm 0.0003$ & -2.94 & 3.83 \\
$50 \% \mathrm{HFIP}$ & $0.0479 \pm 0.0003$ & -2.49 & 3.80 \\
$80 \mathrm{~T}-20 \mathrm{E}{ }^{h}$ & $0.082 \pm 0.005$ & -1.76 & 1.89 \\
$60 \mathrm{~T}-40 \mathrm{E}$ & $0.325 \pm 0.004$ & -0.94 & 0.63 \\
$40 \mathrm{~T}-60 \mathrm{E}$ & $0.909 \pm 0.004$ & -0.34 & -0.48 \\
$20 \mathrm{~T}-80 \mathrm{E}$ & $2.38 \pm 0.03$ & 0.08 & -1.42 \\
\hline
\end{tabular}

${ }^{a}$ Unless otherwise indicated, a $10^{-3} \mathrm{M}$ solution of the substrate in the indicated solvent, containing $0.1 \% \mathrm{CH}_{3} \mathrm{CN} .{ }^{b} \mathrm{On}$ a volume-volume content at $25.0^{\circ} \mathrm{C}$, other component is water. ${ }^{c}$ With associated standard deviations. ${ }^{d}$ Values from ref. 9f. ${ }^{e}$ Values from ref. 9. ${ }^{f}$ Values of $\mathrm{k}(=7.85( \pm 0.04) \times$ $10^{-4} \mathrm{~s}^{-1}$ ) in methanol- $d$ (MeOD), corresponding to a $\mathrm{k}_{\mathrm{MeOH}} / \mathrm{k}_{\mathrm{MeOD}}$ value of $2.14 \pm 0.03$ [with associated standard error (Crumpler, T. B.; Yoh, J. H. Chemical Computations and Error; Wiley: New York, 1940; p 178)]. ${ }^{g}$ Solvent prepared on a weight-weight basis at $25.0{ }^{\circ} \mathrm{C}$. The other component is water. ${ }^{h}$ T-E indicates TFE-EtOH mixtures.
Table 2. Rate constants and activation parameters for the solvolyses of 2,2,2-trichloro-1,1-dimethylethyl chloroformate in pure and aqueous solvents at various temperatures.

\begin{tabular}{|c|c|c|c|c|}
\hline Solvent & $\begin{array}{c}\text { Temp. } \\
\left({ }^{\circ} \mathrm{C}\right)\end{array}$ & $10^{3} \mathrm{k}^{a}\left(\mathrm{~s}^{-1}\right)$ & $\begin{array}{c}\Delta \mathrm{H}^{\neq} \\
\left(\mathrm{kcal} \cdot \mathrm{mol}^{-1}\right)^{b}\end{array}$ & $\begin{array}{c}-\Delta \mathrm{S}^{\neq} \\
\left(\mathrm{cal} \cdot \mathrm{mol}^{-1} \cdot \mathrm{K}^{-1}\right)^{b}\end{array}$ \\
\hline \multirow{4}{*}{$100 \% \mathrm{EtOH}$} & 25 & $0.258 \pm 0.003$ & \multirow{4}{*}{$13.8 \pm 0.5$} & \multirow{4}{*}{$28.6 \pm 1.5$} \\
\hline & 35 & $0.550 \pm 0.003$ & & \\
\hline & 45 & $1.17 \pm 0.02$ & & \\
\hline & 55 & $2.49 \pm 0.03$ & & \\
\hline \multirow{4}{*}{$80 \% \mathrm{EtOH}^{c}$} & 25 & $0.420 \pm 0.003$ & \multirow{4}{*}{$13.3 \pm 0.4$} & \multirow{4}{*}{$29.5 \pm 1.4$} \\
\hline & 35 & $0.870 \pm 0.04$ & & \\
\hline & 45 & $1.81 \pm 0.02$ & & \\
\hline & 55 & $3.73 \pm 0.04$ & & \\
\hline \multirow{4}{*}{$100 \% \mathrm{MeOH}$} & 25 & $0.857 \pm 0.004$ & \multirow{4}{*}{$12.3 \pm 0.4$} & \multirow{4}{*}{$31.4 \pm 1.4$} \\
\hline & 35 & $1.68 \pm 0.04$ & & \\
\hline & 45 & $3.30 \pm 0.03$ & & \\
\hline & 55 & $6.50 \pm 0.05$ & & \\
\hline \multirow{4}{*}{$80 \%$ Acetone $^{c}$} & 25 & $0.0995 \pm 0.0002$ & \multirow{4}{*}{$14.5 \pm 0.5$} & \multirow{4}{*}{$28.2 \pm 1.5$} \\
\hline & 35 & $0.220 \pm 0.002$ & & \\
\hline & 45 & $0.487 \pm 0.003$ & & \\
\hline & 55 & $1.07 \pm 0.02$ & & \\
\hline \multirow{4}{*}{$70 \% \mathrm{TFE}^{d}$} & 25 & $0.00838 \pm 0.00003$ & \multirow{4}{*}{$13.8 \pm 0.6$} & \multirow{4}{*}{$35.5 \pm 2.0$} \\
\hline & 35 & $0.0176 \pm 0.0003$ & & \\
\hline & 45 & $0.0370 \pm 0.0005$ & & \\
\hline & 55 & $0.0813 \pm 0.0004$ & & \\
\hline
\end{tabular}

${ }^{a}$ Averages of three or more runs, with standard deviation. ${ }^{b}$ The activation parameters are accompanied by the standard error. ${ }^{c}$ On a volume-volume content at $25.0{ }^{\circ} \mathrm{C}$. The other component is water. ${ }^{d}$ Solvent prepared on a weight-weight basis at $25.0^{\circ} \mathrm{C}$. The other component is water.

in this instance, the TFE-ethanol points lie toward the middle of the range of the plotted points and have only small deviation such that their omission leads primarily to a small increase in the correlation coefficient value and only very minor changes in the $l$ and $m$ values. Sensitivity values, $l$ and $m$ are tabulated in Table 3, where they are compared with other values reported for similar substrates.

The determination of $l$ and $m$ values will be a valuable source of information concerning the structure of the transition state for these solvolyses. ${ }^{21}$ The $l$ and $m$ values for the solvolysis of I are also compared with recently reported results, as shown in Table 3, involving analysis in terms of equation (2) for the rate constants of solvolyses of $n$-octyl fluoroformate, ${ }^{8}$ phenyl chloroformate,${ }^{16}$ methyl chloroformate, ${ }^{22}$ and ethyl chloroformate. ${ }^{23}$ The $l$ value of 1.42 and the $m$ value of 0.39 for the solvolysis

Table 3. Coefficients from extended Grunwald-Winstein correlations of the solvolyses of 2,2,2-trichloro-1,1-dimethylethyl chloroformate and a comparison with the corresponding values for the solvolyses of the chloroformate esters.

\begin{tabular}{llccccc}
\hline \multicolumn{1}{c}{ Substrate } & $\mathrm{n}^{a}$ & $l^{b}$ & $m^{b}$ & $\mathrm{C}^{c}$ & $l / m$ & $\mathrm{R}^{d}$ \\
\hline $\mathrm{ClCO}_{2} \mathrm{C}\left(\mathrm{CH}_{3}\right)_{2} \mathrm{CCl}_{3}$ & 33 & $1.42 \pm 0.09$ & $0.39 \pm 0.05$ & $0.16 \pm 0.08$ & 3.64 & 0.945 \\
$n-\mathrm{OctOCOF}^{e}$ & 23 & $1.89 \pm 0.13$ & $0.79 \pm 0.06$ & $0.13 \pm 0.34$ & 2.28 & 0.959 \\
$\mathrm{PhOCOCl}$ & 21 & $1.68 \pm 0.10$ & $0.57 \pm 0.06$ & $0.12 \pm 0.41$ & 2.95 & 0.973 \\
$\mathrm{MeOCOCl}^{g}$ & 19 & $1.59 \pm 0.09$ & $0.58 \pm 0.05$ & $0.16 \pm 0.07$ & 2.74 & 0.977 \\
$\mathrm{EtOCOCl}^{h}$ & 28 & $1.56 \pm 0.09$ & $0.55 \pm 0.03$ & $0.19 \pm 0.24$ & 2.84 & 0.967 \\
$4-\mathrm{NO}_{2} \mathrm{BzOCOCl}^{i}$ & 39 & $1.68 \pm 0.06$ & $0.46 \pm 0.04$ & $0.08 \pm 0.08$ & 3.65 & 0.976 \\
\hline
\end{tabular}

${ }^{a}$ Number of solvents included in the correlation. ${ }^{b}$ From eqn. (2), with the associated standard error. ${ }^{c}$ From eqn. (2), accompanied by the standard error of estimate. ${ }^{d}$ Correlation coefficient. ${ }^{e}$ Values from ref. $8 .{ }^{f}$ Values from ref. $16 .{ }^{g}$ Values from ref. $22 .{ }^{h}$ Values from ref. $23 .{ }^{i}$ Values from ref. 20. 


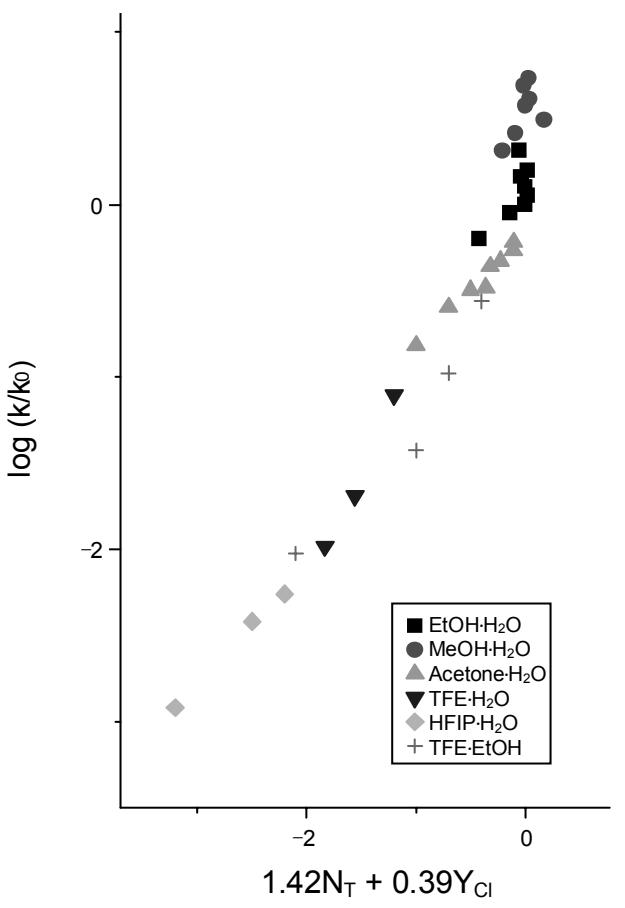

Figure 1. Plot of $\left(\mathrm{k} / \mathrm{k}_{0}\right)$ for 2,2,2-trichloro-1,1-dimethylethyl chloroformate solvolysis at $35.0{ }^{\circ} \mathrm{C}$ against $\left(1.42 \mathrm{~N}_{\mathrm{T}}+0.39 \mathrm{Y}_{\mathrm{Cl}}\right)$, using data for all 33 solvents of the study.

of $\mathbf{I}$ were similar to the previously reported values for the bimolecular solvolyses of the other substrates, which suggests a similar addition-elimination mechanism involving rate-limiting attack by the solvent at the carbonyl carbon atom of $\mathbf{I}$. All of the tabulated values are in the range expected for an additionelimination mechanism and they indicate a large degree of nucleophilic assistance at the transition state of the rls. ${ }^{24}$

The lower $m$ values ( $m=0.39)$ for the solvolysis of 2,2,2trichloro-1,1-dimethylethyl chloroformate, relative to $n$-octyl fluoroformate, ${ }^{8}$ phenyl chloroformate, ${ }^{16}$ methyl chloroformate, ${ }^{22}$ and ethyl chloroformate, ${ }^{23}$ may reflect a reduced need for solvation of the developing negative charge on the carbonyl oxygen, (see Table 3 ).

The $l / m$ ratio has been suggested as a useful mechanistic criterion and the values of 2.2 to 3.8 for entries in Table 3 can be considered to represent addition-elimination. Observation of $m$ values below unity can be considered to reflect an ionization pathway. ${ }^{25}$

For 2,2,2-trichloro-1,1-dimethylethyl chloroformate, the values for the ratio $\mathrm{l} / \mathrm{m}$ of 3.64 is similar to those previously observed for the solvolyses of $n$-octyl fluoroformate, ${ }^{8}$ phenyl chloroformate ${ }^{16}$ methyl chloroformate, ${ }^{22}$ and ethyl chloroformate, ${ }^{23}$ which have been shown to solvolyze over a wide range of solvent type with the addition step of an addition-elimination pathway being rate limiting.

This mechanism is also consistent with general base catalysis by a second $\mathrm{MeOH}$ molecule to an attack of $\mathrm{MeOH}$ on the carbonyl carbon as evidenced by the relatively large kinetic solvent isotope effect observed, $\mathrm{k}_{\mathrm{MeOH}} / \mathrm{k}_{\mathrm{MeOD}}=2.14$. The kinetic solvent isotope effects for the methanolysis of benzoyl chlorides are slightly smaller $\left(\mathrm{k}_{\mathrm{MeOH}} / \mathrm{k}_{\mathrm{MeOD}}=1.2 \sim 1.6\right)$ for the electron- donating substituents but are similar for the electron-withdrawing substituents $\left(\mathrm{k}_{\mathrm{MeOH}} / \mathrm{k}_{\mathrm{MeOD}}=1.7 \sim 2.3\right) .{ }^{26}$ Reported values have indicated that values in these ranges can be considered as good supporting evidence for the postulation of a bimolecular mechanism for the methanolysis.

\section{Conclusions}

Application of the extended Grunwald-Winstein equation led to an $l$ value of 1.42 and an $m$ value of 0.39 . These values are shown (Table 3 ) to be similar to the previously determined values for a mechanism involving rate-limiting addition in an addition-elimination pathway. The large negative entropies of activation were consistent with a bimolecular process. The kinetic solvent isotope effect is also very close to the literature values for the solvolyses of other chloroformate esters and it is consistent with general-base catalysis being super imposed upon a bimolecular process.

\section{Experimental}

Solvents were purified as previously described. ${ }^{24}$ The substrate did not react with the pure acetonitrile within the stock solution. The 2,2,2-trichloro-1,1-dimethylethyl chloroformate (Aldrich 96\%) was used as received.

The kinetic experiments were carried out by allowing a conductivity cell containing $12.5 \mathrm{~mL}$ of solvent to equilibrate, with stirring, in a constant-temperature water bath. A $12 \mu \mathrm{L}$ portion of a $1.0 \mathrm{~mol} \mathrm{dm}^{-3}$ stock solution of $\mathbf{I}$ in acetonitrile was then added. The monitoring of increases in conductivity with time and the calculation of the rate constants (first-order coefficients) were conducted as previously reported. ${ }^{24}$ The multiple regression analyses were performed using commercially available packages.

Acknowledgments. H. J. Koh thanks Professor Dennis N. Kevill (Northern Illinois University, USA) for his devoted advice during preparation and revision of this paper.

\section{References}

1. (a) Bender, M. L. Chem. Rev. 1960, 60, 53. (b) The Chemistry of the Carbonyl Group; Patai, S., Ed.; Interscience: New York, 1966 and 1970; Vols. 1 and 2. (c) Jencks, W. P. Catalysis in Chemistry and Enzymology; McGraw-Hill: New York, 1968. (d) Jencks, W. P. Acc. Chem. Res. 1980, 13, 161. (e) Guthrie, J. P. Acc. Chem. Res. 1983, 16, 22. (f) Baer, S.; Brinkman, E. A.; Brauman, J. I. J. Am. Chem. Soc. 1991, 113, 805. (g) Williams, A. Chem. Soc. Rev. 1994, 23, 93.

2. (a) Yamabe, S.; Minato, T. J. Org. Chem. 1983, 48, 2972. (b) Blake, J. F.; Jorgensen, W. L. J. Am. Chem. Soc. 1987, 109, 3856. (c) Madura, J. D.; Jorgensen, W. L. J. Am. Chem. Soc. 1986, 108, 2517. (d) Park, Y. S.; Kim, C. K.; Lee, B. S.; Lee, I.; Lim, W. M.; Kim, W. K. J. Phys. Org. Chem. 1995, 8, 325.

3. (a) Bentley, T. W.; Jones, R. O. J. Chem. Soc., Perkin Trans. 2 1993, 2351. (b) Bentley, T. W.; Shim, C. S. J. Chem. Soc., Perkin Trans 2 1993, 1659. (c) Song, B. D.; Jencks, W. P. J. Am. Chem. Soc. 1989, 111, 8470. (d) Kivinen, A. The Chemistry of Acyl Halides; Patai, S., Ed.; Interscience: New York, 1972. (e) Queen, A. Can. J. Chem. 1967, 45, 1619.

4. (a) Kim, S. C.; Song, H. S.; Lee, I. J. Korean Chem. Soc. 1979, 
23, 368. (b) Johnson, S. L. Adv. Phys. Org. Chem. 1967, 5, 237. (c) D’Souza, M. J.; Kevill, D. N.; Bentley, T. W.; Devaney, A. C. J. Org. Chem. 1995, 60, 1632.

5. (a) Bond, P. M.; Castro, E. A.; Moodie, R. B. J. Chem. Soc., Perkin Trans. 2 1976, 68. (b) Palling, D. J.; Jencks, W. P. J. Am. Chem. Soc. 1984, 106, 4869.

6. Kyong, J. B.; Yoo, J. S.; Kevill, D. N. J. Org. Chem. 2003, 68, 3425.

7. (a) Faurholt, C.; Gjaldbaek, J. C. Dansk. Tids. Farm 1945, 19, 255. (b) Faurholt, C.; Gjaldbaek, J. C. Chem. Abstr. 1946, 40, 513.

8. Kevill, D. N.; D'Souza, M. J. J. Chem. Soc., Perkin Trans. 22002 , 240.

9. (a) Grunwald, E.; Winstein, S. J. Am. Chem. Soc. 1948, 70, 846. (b) Bentley, T. W.; Llewellyn, G. Prog. Phys. Org. Chem. 1990, 17, 121. (c) Kevill, D. N.; D’Souza, M. J. J. Chem. Res. Synop. 1993, 174. (d) Bentley, T. W.; Carter, G. E. J. Am. Chem. Soc. 1982, 104, 5741. (e) Koo, I. S.; Bentley, T. W.; Kang, D. H.; Lee, I. J. Chem. Soc., Perkin Trans. 2 1991, 296. (f) Winstein, S.; Grunwald, E.; Jones, H. W. J. Am. Chem. Soc. 1951, 73, 2700. (g) Kevill, D. N.; Anderson, S. W. J. Org. Chem. 1991, 56, 1845. (h) Kevill, D. N. In Advances in Quantitative Structure-Property Relationships; Charton, M., Ed.; JAI Press: Greenwich, CT, 1996; Vol. 1, pp 81-115.

10. (a) Castro, E. A.; Ibanez, F.; Salas, M.; Santos, J. G. J. Org. Chem. 1991, 56, 4819. (b) Castro, E. A.; Salas, M.; Santos, J. G. J. Org. Chem. 1994, 59, 30. (c) Chrystiuk, E.; Williams, A. J. Am. Chem. Soc. 1987, 109, 3040.

11. Leffler, J. E.; Grunwald, E. Rates and Equilibria of Organic Reactions; Wiley: New York, 1963; p 222.

12. Choppin, A. R.; Rodgers, J. W. J. Am. Chem. Soc. 1948, 70, 2967.

13. Kevill, D. N.; Weitl, F. L. J. Am. Chem. Soc. 1968, 90, 6416.

14. Kevill, D. N.; Kyong, J. B.; Weitl, F. L. J. Org. Chem. 1990, 55, 4304.

15. (a) Bentley, T. W.; Ebdon, D. N. J. Phys. Org. Chem. 2001, 14, 759. (b) Koh, H. J.; Han, K. L.; Lee, H. W.; Lee, I. J. Org. Chem. 1998, 63, 9834.

16. Kevill, D. N.; D’Souza, M. J. J. Chem. Soc., Perkin Trans. 21997 , 1721.

17. Kyong, J. B.; Won, H.; Kevill, D. N. Int. J. Mol. Sci. 2005, 6, 87.

18. (a) Lee, I.; Sung, D. D.; Uhm, T. S.; Ryu, Z. H. J. Chem. Soc., Perkin Trans. 2 1989, 1697. (b) Yew, K. H.; Koh, H. J.; Lee, H. W.; Lee, I. J. Chem. Soc., Perkin Trans. 2 1995, 2263. (c) Guha, A. K.; Lee, H. W.; Lee, I. J. Chem. Soc., Perkin Trans. 2 1999, 765. (d) Hoque, Md. E. U.; Dey, N. K.; Guha, A. K.; Kim, C. K.; Lee, B.-S.; Lee, H. W. Bull. Korean Chem. Soc. 2007, 28, 1797. (e) Hoque, Md. E. U.; Lee, H. W. Bull. Korean Chem. Soc. 2007, 28,936 .

19. Kevill, D. N.; Miller, B. J. Org. Chem. 2002, 67, 7399.

20. (a) Koo, I. S.; Yang, K. Y.; Kang, K. D.; Lee, I.; Bentley, T. W, J. Chem. Soc., Perkin Trans. 2 1998, 1179. (b) D’Souza, M. J.; Shuman, K. E.; Carter, S. E.; Kevill, D. N. Int. J. Mol. Sci. 2008, 9, 2231.

21. (a) Kyong, J. B.; Park, B. C.; Kim, C. B.; Kevill, D. N. J. Org. Chem. 2000, 65, 8051. (b) Kevill, D. N.; D'Souza, M. J. Collect. Czech. Chem. Commun. 1999, 64, 1790. (c) Bentley, T. W.; Jones, R. O.; Koo, I. S. J. Chem. Soc. Perkin Trans. 2 1994, 753. (d) Kevill, D. N.; D’Souza. M. J. J. Phys. Org. Chem. 2002, 15, 881. (e) Kyong, J. B.; Won, H. S.; Lee, Y. H.; Kevill, D. N. Bull. Korean Chem. Soc. 2005, 26, 661.

22. Kevill, D. N.; Kim, J. C.; Kyong, J. B. J. Chem. Res., Synop. 1999, 150.

23. Kevill, D. N.; D'Souza, M. J. J. Org. Chem. 1998, 63, 2120.

24. Kyong, J. B.; Ryu, S. H.; Kevill, D. N. Int. J. Mol. Sci. 2006, 7, 186.

25. Kyong, J. B.; Rhu, C. J.; Kim, Y. G.; Kevill, D. N. J. Phys. Org. Chem. 2007, 20, 525.

26. Lee, I.; Koh, H. J.; Park, Y. S.; Lee, H. W, J. Chem. Soc., Perkin Trans. 2 1993, 1575. 